\title{
Hereditary pyropoïkilocytosis diagnosis in an infant: benefit of histograms and peripheral smear review
}

\author{
Pyropoïkilocytose héréditaire chez un nourrisson : \\ bénéfices des histogrammes et du frottis sanguin
}

\author{
Victor Bobée \\ Sylvie Daliphard \\ Agnès Lahary \\ Service d'hématologie biologique, \\ $\mathrm{CHU}$ de Rouen, Rouen, France
}

Article received March 26, 2020,

accepted April 15, 2020

A newborn presented with neonatal jaundice and blood count (Sysmex XE) at five days of life showed white blood count of $10.9 \mathrm{G} / \mathrm{L}$, platelet count by impedance of $621 \mathrm{G} / \mathrm{L}$ and hemoglobin of $11.4 \mathrm{~g} / \mathrm{dL}$ with a mean corpuscular volume of $88.9 \mathrm{fL}$. The RBC histogram (figure 1A) displayed a double population, including small particles at the left. The platelet histogram (figure $1 B$ ) showed the presence of large particles in the platelet window. The blood smear (figure $1 C$; original magnification $\times 40$; May-Grünwald Giemsa stain) revealed anisopoikilocytosis, red cell fragments, microspherocytes and elliptocytes. Platelet count by the optical method was $85 \mathrm{G} / \mathrm{L}$, showing a thrombocytopenia of unclear etiology that was masked in impedance. Splenomegaly was not detected at physical examination. Complementary tests highlighted evidence of hemolysis and the diagnosis of hereditary pyropoikilocytosis was considered. Confirmation tests included eosin-5-maleimide binding test by flow cytometry, showing a decreased fluorescence compared with control red blood cells (figure 1D), and osmotic gradient ektacytometry. Gel electrophoresis analysis of erythrocyte membranes was not performed.

Platelet count by impedance was overestimated because of contamination by red cell fragments in the platelet window, thus masking thrombocytopenia. Careful review of the mother's blood smear revealed hereditary elliptocytosis (figure $1 E$ ), with normal blood count and reticulocytes. Histogram analysis and blood smear examination should not be neglected even in newborns, as many of the constitutional hematologic disorders appear in the first year of life.

Conflict of interest: None of the authors has any conflict of interest to disclose concerning this article.
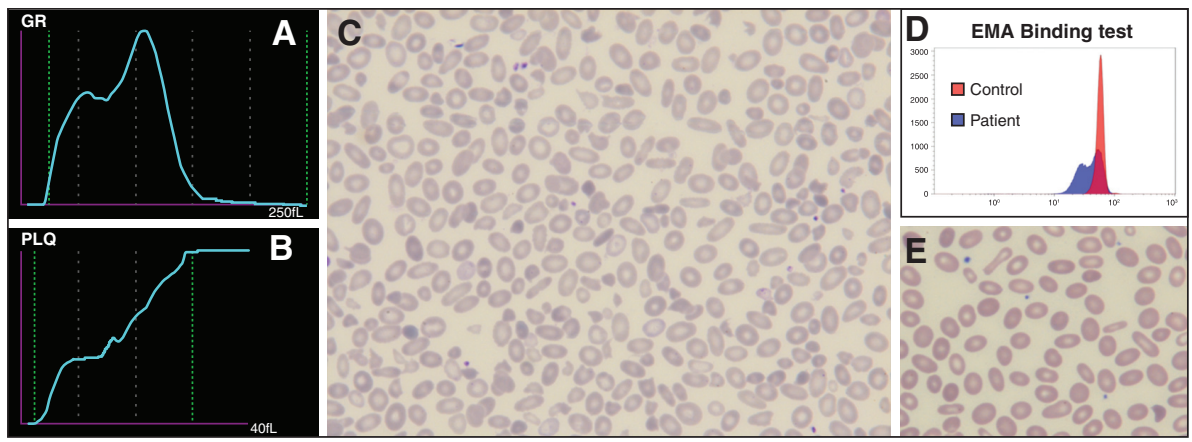

Figure 1. (A) Red blood cell histogram and (B) Platelet histogram, Sysmex XE. (C) Blood smear of the patient, original magnification $x 40$, May-Grünwald Giemsa stain. (D) EMA binding test by flow cytometry. (E) Blood smear of the patient's mother. 